\title{
Talleres de danza del Instituto Politécnico Nacional
}

(ca. 1968-1988)

Roxana-Guadalupe Ramos-Villalobos

\section{RESUMEN}

En este artículo se pone atención en los talleres de danza del Instituto Politécnico Nacional (IPN) que se establecieron después del movimiento estudiantil de 1968 y para su estudio se abren las siguientes preguntas ¿Qué son y cómo funcionan los talleres artísticos en el IPN? ¿Qué importancia le han dado a la danza? ¿Qué programas dancísticos se han puesto en marcha en el periodo que abarca este estudio? Para entender el propósito y funcionamiento de los talleres fue necesario recurrir a la noción de taller de Antonio Santoni y trabajar dos tipos de fuentes, documentales y testimoniales; las primeras: las obtuve del archivo histórico del IPN y las testimoniales, gracias a las entrevistas que me concedieron siete maestros de danza de la Institución. Para explicar los hallazgos este apartado se divide en tres secciones: en la primera se estudian los antecedentes y los procesos que permitieron el surgimiento de los talleres; en la segunda se revisan los procesos y avances de los talleres de danza durante el periodo 1969-1979, y en la última sección se analiza el surgimiento de las coordinaciones y se identifican los programas dancísticos que se crearon.

Palabras clave: historia de la educación, IPN, talleres, danza, México. 


\section{RESUMO}

Neste artigo se analisa as oficinas de dança do Instituto Politécnico Nacional (IPN) que se estabeleceram despois do movimento estudantil de 1968 e para seu estudo se abrem as seguintes preguntas: O que são e como funcionam as oficinas artísticas no IPN? Que importância se dá à dança nessas oficinas? Que programas de dança têm se desenvolvido no período que abarca este estudo? Para entender o propósito e funcionamento das oficinas foi necessário recorrer à noção de oficina de Antonio Santoni e trabalhar dois tipos de fontes, documentais e testemunhais; as primeiras foram obtidas do arquivo histórico do IPN e as segundas, graças às entrevistas que me concederam sete professores de dança da Instituição. Para explicar as descobertas esta parte se divide em três seções: na primeira, se estudam os antecedentes e os processos que permitiram o surgimento das oficinas; na segunda, se revisam os processos e avances das oficinas de dança durante o período 1969-1979, e na última seção, se analisa o surgimento das coordenações e se identificam os programas de dança que se criaram.

Palavras chave: história da educação, IPN, oficinas, dança, México.

\section{Dance Workshops at the National Polytechnic Institute (ca. 1968-1988)}

\section{ABSTRACT}

This article focuses on the dance workshops that were established at the National Polytechnic Institute (Instituto Politécnico Nacional, IPN) after the student movement of 1968. In order to study them, the following questions are raised: What were the artistic workshops at the IPN and how did they function? What importance have they given to dance? What dance programs have been implemented during the period covered by this study? To understand the purpose and functioning of the workshops, it was necessary to refer to Antonio Santoni's notion of workshop and to work with two types of sources, documentary and testimonial; the former were obtained from the IPN's historical archive and the testimonial, thanks to the interviews granted to the author by seven dance teachers of the Institution. In order to explain the findings, this section is divided into three sections: in the first, the background and processes that allowed the emergence of the workshops are analyzed; in the second, the autor reviews the processes and progress of the dance workshops during the period 1969-1979; and in the last section, the focus is set on the emergence of the coordinations and the dance programs that were created.

Key words: history of education, IPN, workshops, dance, Mexico. 


\section{Antecedentes (1958 a 1968)}

En 1958 iniciaron los cursos de danza folclórica en el Instituto Politécnico Nacional (IPN) en la Escuela Superior de Medicina, ubicada en el Casco de Santo Tomás, en la Ciudad de México, con el aval del área de difusión cultural y con el propósito de "encauzar a los estudiantes en las manifestaciones del arte" (Calvillo et al., 2006: 216).

Marcelo Torreblanca ${ }^{1}$ impartió las primeras clases de danza y se le considera un pionero en la transmisión de esta disciplina en distintas instituciones: "en el IPN, en la Juventud Mexicana, la Normal de Maestros, en la Pedagógica; en todos lados abría brecha y después se iba; en el IPN estuvo poco tiempo, pero invitó a varios maestros para que dieran clases" (Gutiérrez-Badillo, 2019).

La maestra Beatriz Carrillo Robles ${ }^{2}$ fue la encargada de la danza clásica y de poner en marcha una serie de programas como "funciones de danza en la Plaza del Carrillón y en el Cuadrilátero de Santo Tomás los sábados y domingos" (IPN, 2008) y de presentaciones para el Canal 11 de televisión, donde ella también bailó (Mendoza, 1990a: 22-23).

Los cursos de danza al principio se impartieron de manera temporal y más adelante se instituyeron permanentemente debido al éxito obtenido entre los jóvenes politécnicos. La primera generación de maestros de danza folclórica estuvo integrada por: José Ramírez Silva, María Eugenia Salas, Otila Cuesta Grajales, Rosa Elia Serra, Rosa María González Prado, Edith Marlén Martínez, María Zoila Nava Meza, Elena Marroquí e Hilda Aurora Granados Almeida (IPN, 2008). La mayoría de ellos fueron docentes del IPN por varios años.

Los maestros José Ramírez Silva y María Eugenia Salas ingresaron en 1963; ambos eran profesores de danza folclórica y laboraron en el Politécnico durante 36 años hasta que se jubilaron en 1999. Los dos transmitieron sus conocimientos en diferentes planteles, el profesor Ramírez dio clases en la Vocacional número 7, en la Escuela Superior de Ingeniería Mecánica y Eléctrica (ESIME) y en el CECyT número 5 "Benito Juárez" (Ramírez, 2019), y la maestra Salas, en la Escuela Superior de Ingeniería Química e Industrias Extractivas (ESIQUIE) (Mendoza-Pastrana, 2018).

José y María Eugenia se conocieron en un desfile del 20 de noviembre en Tampico, Tamaulipas y "ahí se enamoraron y se casaron, fueron pareja en la vida y en la danza" (Ramírez, 2019) y como compartían el mismo espacio laboral unieron sus grupos y formaron el Grupo Representativo de Danza Folclórica del IPN con 20 bailarines. Dicho conjunto bailó en distintas instituciones y auditorios incluyendo el Alejo Peralta, de este espacio uno de los integrantes platica que:

\begin{abstract}
Al principio el Auditorio Alejo Peralta era de herrería, un galerón muy grotesco, pero fuerte. Era tan grande que si para las danzas llevábamos palomas, cuando las soltábamos ahí se quedaban; para sacarlas teníamos que llevar cohetes o veneno, pero como había una maestra que protegía a los animales no lo permitía [...] para sacarlas se contrató a un señor que tenía un halcón, lo soltó y las palomas se fueron (Mendoza-Pastrana, 2019).
\end{abstract}

Varios de los bailarines recuerdan haber vivido anécdotas inolvidables, por ejemplo, cuando dieron una función en la Escuela Superior de Comercio y Administración (ESCA) de Santo Tomás y conocieron a Tata Nacho, uno de ellos cuenta:

\footnotetext{
${ }^{1}$ Marcelo Torreblanca (1907-1986). Profesor de educación física, danzante y docente de danza folclórica. Trabajó en diversas instituciones públicas abriendo brecha para la transmisión y difusión de la danza folclórica mexicana.

${ }^{2}$ Beatriz Carrillo Robles. Bailarina, docente y coreógrafa de danza clásica que trabajó en el IPN como coordinadora de los programas de danza clásica en Canal 11 y como coordinadora de los cursos de danza clásica y moderna en el IPN (Mendoza, 1990a: 21-24).
} 
Estábamos esperando nuestra participación. Íbamos a bailar Jalisco. A mi lado estaba un señor, ya grande, vestido de charro, sin sombrero, a quien le preguntamos: "por qué no usa sombrero" y él nos dijo: "porque yo dirijo la Orquesta Típica, nosotros los vamos a acompañar, ¿no me conocen? Soy Tata Nacho". Me arrepiento de no haberme tomado una foto con él. Nunca olvidaré que ese día bailamos acompañados por la Orquesta Típica de Tata Nacho (Mendoza-Pastrana, 2018).

La mayor parte de los integrantes de este Grupo terminaron sus estudios en el Politécnico y se graduaron de ingenieros, médicos y arquitectos e incluso ocuparon puestos directivos, como: "Óscar Joffre Velázquez, quien fue director del IPN de 1989-1994 [y] Sergio Viñals Padilla, quien también ocupó el cargo de director de la Institución de 1976 a 1979" (Mendoza-Pastrana, 2019); en dicho conjunto también bailó la que sería la esposa de Óscar Joffre Velázquez, así como Martín Mendoza Pastrana y Miguel Ángel Gutiérrez Badillo, quienes se dedicaron profesionalmente a la danza y dieron clases en el Instituto. Miguel Ángel Gutiérrez, cuando ya era docente del IPN, recuerda el día en que Sergio Viñals Padilla, siendo director de la institución, visitó el CECyT "Ricardo Flores Magón":

Estábamos haciendo valla para que pasara el director del IPN cuando nos indicaron: "después de la ceremonia va a haber una comida, ustedes no están invitados". En eso entró el ingeniero Sergio Viñals y me dijo: "Tú bailabas con Pepe ¿no te acuerdas de mí? Yo ya no bailaba con ustedes, pero visité el grupo en varias ocasiones y te veía bailar. Vamos a platicar, te invito a comer". El director del CECyT "Ricardo Flores Magón” se quedó sorprendido de que el ingeniero Viñals me conocía y de que además me invitó a comer (Gutiérrez-Badillo, 2019).

El Grupo Representativo de Danza Folklórica estuvo vigente diez años (1965-1975) a pesar de los embates que vivió en 1968, cuando un grupo de "militares entró a la bodega donde guardaban su equipo de trabajo (vestuario, parafernalia, escenografia y material fonográfico) y lo destrozó [...] pasaron varios meses, casi un año" (Mendoza-Pastrana, 2018) para que el Grupo pudiera recobrarse y reanudara su trabajo.

Este Grupo, durante su vigencia, tuvo la oportunidad de viajar y conocer varios estados de la República y de presentarse en distintos foros y auditorios gracias a que sus maestros fomentaron un ambiente de unión y solidaridad "casi como si fueran familia" (Mendoza-Pastrana, 2019) lo que propició que varios de ellos, hasta la fecha, se comuniquen.

Un fenómeno que tuvo lugar en estos años fue la participación de los porros en la promoción y organización de las actividades artísticas y culturales, dado que algunos de ellos formaban parte de los ateneos y de la Asociación de Ateneos y Seminarios. Las opiniones con respecto a su intervención eran encontradas. El hijo de José Ramírez Silva comentó que "a pesar de los porros, sus papás lograron muy buenos resultados con los estudiantes de danza" (Ramírez, 2019), en cambio la maestra Esperanza Gutiérrez opina que:

En la Escuela Superior de Ingeniería, Química e Industrias Extractivas los organizadores de las actividades artísticas y culturales eran los porros. No eran malos, incluso pasaban a los salones y les preguntaban a los estudiantes si querían aprender danza y organizaban los cursos. Era raro, pero formaban parte de la sociedad de alumnos y se involucraban en la organización de los eventos y actividades artísticas (Gutiérrez, 2019).

La actividad de los porros disminuyó después del movimiento del 68 debido a que la Institución tomó acciones para reducir su intervención, una de ellas fue no darles más apoyo ni a ellos ni a la Asociación de Ateneos y Seminarios, lo que propició que la difusión de la cultura quedara totalmente en manos de las autoridades del IPN. 


\section{Talleres de danza del IPN (1969 a 1979)}

Después del movimiento estudiantil del 68, el IPN modificó los objetivos, programas y actividades del área de Difusión Cultural y a los cursos los denominó talleres ${ }^{3}$ artísticos. Se abrieron talleres de danza folclórica, clásica y moderna, y para intensificar la difusión de esta última, Antonio Rodríguez, jefe del Departamento de Difusión Cultural, invitó en 1969 a Helena Jordán ${ }^{4}$ para que se hiciera cargo del área.

La participación de Helena Jordán en el Politécnico fue por un periodo corto (ca. 1969-1972), lapso en que logró realizar varias actividades: organizó una serie de charlas sobre danza, un festival en el teatro de la Unidad Cultural Zacatenco, un homenaje al coreógrafo y bailarín mexicano José Limón; apuntaló la creación de grupos de danza moderna del Politécnico y creó el Grupo Representativo de Danza Moderna del IPN, que posteriormente llevó el nombre de Taller Espacios (Mendoza, 1990b: 48).

Para danza folclórica, el IPN contrató a más maestros de la especialidad, entre ellos a Alejandro Guzmán Miranda, Cecilia Valeria Rodríguez Mireles, Enrique Vargas Torres, Joel Castañeda Hernández, Leticia Salas Aguirre, Lourdes de Gante, María de la Luz Pulido Salas, Miguel Ángel Gutiérrez-Badillo, Rafael Téllez Girón y Raúl Ballinas Martínez, quienes se sumaron a los que ya daban clases desde la década de los sesenta.
En particular, Miguel Ángel Gutiérrez, alumno de José Ramírez Silvia y de María Eugenia Salas, tuvo la fortuna de que lo recomendaran para que se integrara a la planta docente del IPN. De este hecho el maestro Gutiérrez recuerda que José Ramírez Silva le dijo "necesitamos que vayas a la escuela de Taxqueña, la van a abrir, requieren un grupo de danza, organízalo" (Gutiérrez-Badillo, 2019). El profesor Miguel Ángel se integró al IPN y transmitió sus conocimientos por 30 años hasta que se jubiló.

En este periodo (1969-1979) se abrieron los talleres de danza, teatro, música, canto, artes plásticas y fotografía; estaban dirigidos a todos los estudiantes y se ofrecieron como una actividad optativa, por eso la institución cuidó que los horarios no se empalmaran con otras materias. Los espacios destinados para impartir los talleres fueron los auditorios y los foros de las escuelas, los salones de las clases teóricas, los salones de usos múltiples, los pasillos e incluso debajo de las escaleras. En Zacatenco el salón de usos múltiples estaba disponible para todos los talleres artísticos.

En ese tiempo el área de danza padeció por falta de presupuesto, situación que mejoró paulatinamente a medida que las autoridades se fueron sensibilizando y reconocieron los beneficios de la práctica artística. Mientras tanto, la falta de recursos afectó tres rubros: la compra de vestuario, la organización de cursos con informantes ${ }^{5}$ y las prácticas de campo. ${ }^{6}$

\footnotetext{
${ }^{3}$ Del origen del taller el profesor e historiador italiano Antonio Santoni dice, "nadie nace sabiendo"(Santoni, 2009: 64) y explica que "para instruir en la manera de realizar incluso las actividades más remotas, como fue encender el fuego, es necesario dar a conocer una serie de operaciones y ritos que requerían habilidades complejas y, por eso, era un arte que se debía transmitir con sus creencias esotéricas y sus implicaciones prácticas [actividades que] antecedieron por alrededor de un millón de años a las primeras escuelas y a los primeros maestros como lo testimonian las tablas de los Sumerios" (ibid.). Por lo tanto, se puede decir que la enseñanza de actividades prioritarias como la pesca, la ordeña, el pastoreo, el picar piedra, estuvo inicialmente en manos de los padres de familia, quienes hacían las veces de instructor y/o maestro. Tiempo después, cuando las comunidades sedentarias crecieron y se inició el intercambio de mercancías y comenzó la división del trabajo, fue necesario aprender nuevas artes. El rol de instructor se separó así del rol de padre. "Nació entonces el 'taller' artesanal con una función productora de mercancías, pero también transmisora del 'saber hacer' [...] y entonces el artesano sucedió al padre instructor-educador (ibid.).

${ }^{4}$ Helena Jordán (México, D. F., 1932), bailarina, docente, directora y coreógrafa (Mendoza, 1990b: 47-50).

${ }^{5}$ Un informante es un danzante o maestro de danza de una región específica de la República Mexicana que transmite a los docentes y/o estudiantes de danza, las danzas y bailes de su región; los cursos con informantes generalmente se dan en tres o cuatro días; en ellos los participantes registran la información proporcionada para después aprenderla y trasladarla al salón de danza o al escenario. ${ }^{6}$ Es una actividad extra aula organizada por el profesor de danza folclórica a fin de acudir con los estudiantes a un lugar específico de la República Mexicana a conocer los procesos rituales, festivos, espacios sociales y culturales de los que la danza tradicional surge y forma parte; en la práctica de campo los participantes registran la información para después analizarla, aprenderla, asimilarla y, si es el caso, escenificarla.
} 
En un folleto del IPN se reconoce que el principal problema para la compra de vestuario era la carencia de recursos económicos, por eso el vestuario:

se sustituye con faldas de ensayo y blusas de uniforme [...] es importante resaltar la labor de los profesores que dirigen los talleres de danza porque buscan alternativas para vestir lo más original según la danza [...] el profesor investiga y contacta con gente del arte textil que elabora indumentaria original de su región y con artesanos de máscaras, sombreros [...] para fomentar la verdadera cultura dancística y no caer en imitaciones que no aportan nada al arte y el alumno esté consciente y orgulloso de portar los trajes de México (IPN, 2008).

Los jóvenes se daban cuenta de que los maestros hacían todo lo posible para que portaran el vestuario original y, en ese sentido, la labor de los profesores "era encomiable [...] José Ramírez y María Eugenia Salas por amor al arte o por orgullo, siempre terminaban poniendo de su bolsa" (Mendoza-Pastrana, 2019).

El interés por los estudiantes provenía de la mayor parte de los profesores, no sólo para la adquisición de vestuario, sino también para la organización de prácticas de campo y de cursos con informantes; los maestros estaban convencidos de que era muy importante que los estudiantes conocieran y se familiarizaran con todas aquellas actividades relacionadas con la investigación.

Miguel Ángel Gutiérrez platica su experiencia con el maestro Maximiliano, informante de la Danza de la pluma de Oaxaca.

En 1976 el director de la escuela donde trabajaba me pidió que ya no repitiera el mismo repertorio de años anteriores, pero le comenté que para trabajar otras danzas necesitaba presupuesto y que me gustaría estudiar la Danza de la pluma, pero requería \$15 000. Jorge Hernández Pizaña, jefe de Difusión Cultural, autorizó el presupuesto y me fui a
Cuilápam de Guerrero, Oaxaca para aprender la música, el vestuario y la danza con el maestro Maximiliano. Puse la danza respetando los diálogos, incluí a los soldados, al bando mexicano y al español, a Hernán Cortés y a la Malinche como se hacía en el pueblo; el público se quedó sorprendido [...] A partir de ese momento el profesor Hernández Pizaña siempre me apoyó (Gutiérrez-Badillo, 2019).

Otro aprendizaje para los jóvenes fue la visita a Oaxaca con motivo de la Guelaguetza y al respecto el maestro Gutiérrez dice:

Llevé a mis alumnos a bailar a la Guelaguetza durante 20 años [...] nos invitaban a la calenda; bailaban con los danzantes de Juquila [...] un pueblo que en el siglo XVIII fue rasgado por el huracán, por eso un sacerdote invitó a sus pobladores a resguardarse en Juquila [...] de ser costeños subieron 1200 metros. Los pobladores nunca olvidaron su cultura chatina, hablan chatino, viven en la Sierra, pero siguen siendo costeños. Creen en la virgen de Juquila y van a su iglesia [...] El vestuario lo tomaron de un pueblo que se llama Santiago Yautepec, pero sus habitantes se molestaron, entonces yo diseñé y corté el vestuario actual para los pobladores de Juquila, que es una falda costeña (Gutiérrez-Badillo, 2019).

Los jóvenes bailarines también tuvieron la oportunidad de visitar otras festividades; el profesor Alejandro Guzmán Miranda los "llevaba a prácticas de campo y les trasmitía su interés por la investigación [...] En una ocasión estudiaron la danza de los viejitos de Jarácuaro, Michoacán” (Gutiérrez, 2019). Las prácticas de campo finalmente se convirtieron en un recurso didáctico para que los estudiantes compararan y decidieran cómo bailar una danza o un son, la estrategia de uno de los maestros era la siguiente:

llevaba al grupo completo al lugar de la danza y a los alumnos les decía: "yo aprendí con el maestro 
Juanelo en Pinotepa Nacional, él baila como ustedes bailan, pero quiero que comparen; ahora los voy a llevar con Israel Baños y van a ver como baila él, baila diferente de Juanelo. Después de conocer las dos posibilidades ustedes van a decidir cómo vamos a bailar "Pinotepa Nacional". Juanelo ya murió - tuvo el prestigio de ser el mejor bailador de chilenas - , hasta Álvaro Carrillo le compuso una pieza musical (Gutiérrez-Badillo, 2019).

A muchos de los estudiantes del IPN practicar danza los marcó en diferentes sentidos. A algunos les permitió reconocer la importancia del orden, la colaboración, la solidaridad y la puntualidad para alcanzar una meta. José Luis Rodríguez subraya la necesidad de la disciplina dancística "sobre todo, para los jóvenes que estudian en los CECyT ya que se encuentran en una edad en la que algunos no saben qué quieren. La danza como disciplina tiene repercusiones positivas en la carrera y en la familia, estrecha lazos familiares; en varias ocasiones los papás iban a las funciones y preguntaban qué necesitan, cómo ayudamos" (Rodríguez, 2019).

El maestro Martín comenta que, además de la disciplina, la danza "les da a los jóvenes otra visión de vida; no sólo es recreación, es cultura, con la danza se aprende historia de México, gastronomía, vestuario, música, artes plásticas, se estudian las culturas indígenas, las etnias, es por eso que la danza colabora con la educación integral de los estudiantes del IPN" (Mendoza-Pastrana, 2019). En algunos estudiantes, incluso, la danza mejoró su desempeño social, como en el caso de Leonel Vázquez quien:

era un joven que tenía problemas para relacionarse con sus compañeros debido a que lo discriminaban porque era chinanteco. Al principio iba a la clase y se sentaba en el salón sólo a vernos bailar. Yo le preguntaba: ¿por qué no bailas? Y él me respondía: 'me da pena'. Un día participamos en la celebración del Día Internacional de la Danza con la Danza de Paloteros. Leonel dijo: yo los ayudo, pero no voy a bailar. Entonces le pedí que se llevara el estandarte y que mientras bailábamos se quedara firme. Esa fue su primera participación. Todos lo felicitaron y él empezó a tomar confianza. Después monté los Bailes de Ejutla y fuimos al carnaval. Leonel se metió al carnaval, a la búsqueda del tesoro, todos participaron en la calenda con los viejos, con los Tilicheros, tomaron cerveza y que llegan los del grupo de Ejutla y les dicen: "ahora van a aprender a bailar las chilenas" y empezaron a bailar. A Leonel como que se le destrabaron los complejos y empezó a bailar, se soltó. Yo estaba con el presidente municipal y el directivo del grupo y les platiqué que Leonel no bailaba. Ellos comentaron que bailaba muy bien. Se le quitó el prejuicio, llegó a dar clases de chilena y estudió antropología en la UNAM. Él ya murió. Leonel bailando era un garbanzo de a libra (Gutiérrez-Badillo, 2019).

El compromiso de los profesores y el interés de los jóvenes politécnicos por la práctica de la danza generó en esos años la creación de grupos de danza en diferentes escuelas, algunos de los más sobresalientes fueron el de la Escuela Superior de Comercio y Administración que contó con la contribución en dos ocasiones (1972 y 1977) de Arturo Ponce Pedraza, jefe del departamento de Difusión Cultural, quien les elaboró las escenografías y diapositivas para las puestas en escena de Las mascaritas (Leonardo Velázquez) y de Ritual; ambas coreografías resultado del trabajo de investigación de los estudiantes.

Dos conjuntos más que se presentaron continuamente en los foros del IPN fueron el del Casco de Santo Tomás, guiado por Rosa Elia Serra, y el de la Escuela de Turismo, dirigido por Luz María Pulido Salas. El conjunto folclórico a cargo de Otila Cuesta Grajales, con el tiempo, llegó a ser el Ballet Folklórico del IPN de la Unidad Cultural Zacatenco y estuvo formado por estudiantes del IPN y por bailarines del 
Instituto Mexicano del Seguro Social (IMSS). ${ }^{7}$ José Luis Rodríguez Cuevas, bailarín del Ballet Folklórico del IPN comentó:

La maestra Otila era una persona muy preparada, muy gentil, estudió en la Escuela Nacional de Danza, su formación era en danza clásica, tenía un cuerpo muy bonito, muy finita, de bailarina de danza clásica, no sé por qué decidió continuar en la danza folclórica; para la maestra todo mi respeto y admiración, tenía muchos conocimientos; en el Ballet Folklórico del IPN abarcamos todos los estados, pero el que más le gustaba era Chiapas, porque era su estado natal. Desgraciadamente ella se enfermó y finalmente se acabó la compañía (Rodríguez, 2019).

En 1975, a casi 20 años de que el maestro Marcelo Torreblanca iniciara los cursos de danza, la Institución le organizó un homenaje con la presencia de varios grupos: el de Miguel Ángel Gutiérrez Badillo bailó la danza de La Pluma, el conjunto de la profesora Aurora Granados Almeida llevó a escena Los Huahuas y el del profesor Cuauhtémoc de la Normal de Maestros también presentó la danza de La Pluma (Gutiérrez-Badillo, 2021).

\section{Talleres de danza del IPN (ca. 1980-1988)}

A principios de la década de los ochenta la Jefatura de Difusión Cultural del Politécnico estaba a cargo de Jorge Hernández Pizaña, quien tenía sus oficinas en Zacatenco. Esta jefatura estaba integrada por divisiones y una de ellas estaba al pendiente del funcionamiento de los talleres artísticos y culturales a través de las coordinaciones de danza folclórica, danza clásica y moderna, teatro, música, literatura, artes plásticas, cine y fotografía. Como parte de sus tareas, las coordinaciones debían:

cumplir con el programa operativo anual del IPN que incluye la producción, difusión y preservación de la cultura politécnica, difundir la cultura y sus valores, fortalecer y preservar la identidad nacional, coadyuvar a la formación integral del estudiante politécnico, promover la práctica de actividades artísticas y recreativas entre los jóvenes, ejercitar las destrezas de cada uno de los estudiantes de acuerdo con el taller seleccionado y que el joven estudiante politécnico se reconozca como un ser individual y social (IPN, 2008).

$\mathrm{Al}$ frente de la coordinación de teatro estaba Mario del Razo quien poseía una amplia experiencia, por lo que además de fungir como coordinador de su especialidad dirigía "un taller de teatro que trabajaba dos veces a la semana" (Mendoza-Pastrana, 2019).

$\mathrm{El}$ coordinador de teatro fue un personaje clave para la difusión de las actividades artísticas y culturales, su colaboradora más cercana fue Silvia López López, quien había sido bailarina del Ballet Folklórico de México de Silvia Lozano; ambos hicieron una buena mancuerna y tuvieron un inmejorable desempeño. Un logro de su administración fue que consiguieron apoyo del Fondo Nacional para el Desarrollo de la Danza Popular Mexicana (FONADAN) ${ }^{8}$ para nutrir de maestros al IPN.

\footnotetext{
${ }^{7}$ El 10 de marzo de 2006 el IPN, durante la conmemoración de su 70 Aniversario(1936-2006), le rindió un homenaje a Otila Cuesta Grajales por su trabajo como directora del Ballet Folklórico del IPNy por su trayectoria en la difusión de la cultura y la danza. En este homenaje a la maestra Otila se le entregó una placa conmemorativa con el nombre de los bailarines: Patricia Camacho Guerrero, Julieta Chilpa Navarrete, María Teresa Delgado Bravo, Silvia Lucrecia Franco Huerta, Luz María González Aguilar, María Teresa González Vargas, Margarita Guzmán Montoya, Ana Magdalena López García, Esperanza López García, María Estela Márquez García, Dolores Maza Lezama, Cecilia Sánchez Albarrán, Silvia Santillán Hernández, Socorro Rubio Curtis, José Manuel Cruz Palacios, Rodolfo López Cerdán, José Luis Mendoza Pérez, Gregorio Noguez Monroy, José Luis Rodríguez Cuevas, Rodrigo Sandoval Cervantes, Andrés Sánchez Vallejo, Lauro Silva Ros, Hugo Zúñiga Reséndiz. ${ }^{8}$ FONADAN fue un fideicomiso que se creó el 23 de noviembre de 1972 en el sexenio de Luis Echeverría Âlvarez y que empezó a trabajar en 1973 bajo una estructura constituida por el director del INBA, un suplente, y una delegada, que fue Josefina Lavalle, y su propósito fue la investigación, registro, preservación y difusión de las danzas tradicionales mexicanas.
} 
Mario del Razo invitó a Martín Mendoza Pastrana como coordinador de danza folclórica, cargo que desempeñó de 1980 a 1992; en danza clásica y moderna estuvo Beatriz Carrillo. El maestro Mendoza aceptó el reto de la coordinación de danza folclórica a sabiendas de que varios maestros del IPN contaban con una amplia trayectoria. Del día que tomó posesión del cargo, el nuevo coordinador platica:

Las autoridades del Poli me dijeron "va a haber una junta y tienes que tener cuidado porque vienen maestros muy experimentados que tienen base en la institución, a ver cómo se portan" yo les contesté: "no le temo a nada" [...] En la junta estaban mis maestros, quienes pasaron a ser mis subordinados y otros que habían sido mis compañeros; tuvieron un gesto muy amable; me felicitaron y me dijeron: "queremos que sepas que cuentas con nosotros". Me apoyaron mucho (Mendoza-Pastrana, 2018).

Durante el tiempo en que Martín Mendoza fue coordinador contó con la colaboración de Verónica Aguilar Barbosa, quien fungió como su asistente; ella también estudió danza folclórica en el IMSS y en la Escuela de Danza del Departamento del Distrito Federal que dirigía Héctor Fink (Mendoza-Pastrana, 2021).

Uno de los problemas que el profesor Mendoza enfrentó fue que el número de talleres era insuficiente debido a la falta de plazas y presupuesto. Problemática que se solventó parcialmente cuando se crearon los contratos. Las contrataciones para los maestros eran de dos tipos: de base y contrato. Los maestros de base, como la mayor parte de los docentes del IPN, podían jubilarse y el acuerdo lo pactaban con el director de la escuela en donde trabajaban; los maestros que prestaban su servicio por contrato eran seleccionados por el coordinador de la disciplina:

si un profesor ingresaba al IPN por contrato, el salario era bajo; a pesar de eso, varios trabajaron como docentes; ése era el verdadero amor al arte y no a la nómina. Algunos maestros laboraron durante varios años y otros, como fue el caso de Miguel Ángel Gutiérrez Badillo y de Abraham Cureño, consiguieron la base y se jubilaron [El proceso de admisión consistía en que] se contrataba a un maestro por su experiencia probada en el área o porque al dar clases frente grupo se constataba el conocimiento y dominio que tenía de la materia. A los profesores de danza que firmaban un contrato se les pagaban 3000 pesos igual que a los maestros de teatro. Los maestros de base ganaban más (Mendoza-Pastrana, 2019).

Con los nuevos contratos y plazas, el número de profesores de danza folclórica se incrementó. El coordinador de danza folclórica explica: "Llegué a tener a mi cargo a 60 maestros: 14 de las escuelas vocacionales y 20 de las profesionales y en cada escuela teníamos un taller; algunos planteles contaban con dos maestros de danza folclórica. Mi coordinación era la más grande" (Mendoza-Pastrana, 2018).

Los maestros que se contrataron a finales de la década de los setenta y principios de los ochenta fueron Abraham Cureño, Angélica Millán, Antolín René González, Antonio Mares Ramírez, Aurea Luisa Merino Ramos, Carlos Rodríguez Rocha, Carlos Vázquez Valdés, Cecilia Campos Domínguez, Claudio A. Rivera Hernández, Emma Orduña Castrejón, Esperanza Gutiérrez Peña, Gustavo Adolfo Quezada Rosales, Honoria Baena Cerón, Isabel García González, José Luis Rodríguez Cuevas, Juan Tomás Piedras Ortiz, Julio César González Calderón, Leticia Valdés Monroy, Manuel Salvador Sánchez Castillo, Margarita Elena Aguilar Rosa, María Cristina Estrada Navarro, María de la Luz Murguía, María de Lourdes Quintero Rodríguez, María Teresa González Vargas, Martha Elena González Esquivel, Martha Limón Sarmiento, Ofelia Elizabeth Campos Solona y Pablo Parga Parga. 
Tabla 1. Nombre de las escuelas que contaban con profesor de danza folclórica y/o moderna

\begin{tabular}{|c|c|c|}
\hline Escuela & Profesor & Núm. de estudiantes \\
\hline Escuela Superior de Comercio y Administración, Santo Tomás & Martha Limón Sarmiento & 40 \\
\hline Escuela Superior de Comercio y Administración, Santo Tomás & Martha Limón Sarmiento & 40 \\
\hline Escuela Superior de Turismo & Rafael Téllez Girón & 60 \\
\hline Escuela Nacional de Ciencias Biológicas & Enrique Vargas & 35 \\
\hline Escuela Superior de Economía & Raúl Ballinas Martínez & 25 \\
\hline $\begin{array}{l}\text { Unidad Profesional Interdisciplinaria de Ingeniería y Ciencias Sociales y } \\
\text { Administrativas }\end{array}$ & $\begin{array}{l}\text { Joel Castañeda H.Patricia Estrada, danza } \\
\text { contemporánea }\end{array}$ & 25 \\
\hline Escuela Superior de Ingeniería Textil & Esperanza Gutiérrez Peña & - \\
\hline Escuela Superior de Ingeniería y Arquitectura, Zacatenco & Isabel García y Mora Chaparro & $\begin{array}{l}\text { Se impartía Danza moderna y } \\
\text { Gimnasia rítmica }\end{array}$ \\
\hline Escuela Superior de Ingeniería Mecánica y Eléctrica, Xocongo & Cecilia Campos Domínguez & 30 \\
\hline Escuela Superior de Medicina & $\begin{array}{l}\text { Rosa Elia Serra (danza folclórica) y Bertha } \\
\text { Socorro Balderrama (danza moderna) }\end{array}$ & 40 \\
\hline CECYT Wilfrido Massieu & Ema Orduña y Guadalupe González & 60 \\
\hline СЕСУт Miguel Othón de Mendizábal & Rosa María González Prado & 30 \\
\hline СЕСУт Luis Enrique Erro & María de Lourdes Quintero Rodríguez & 60 \\
\hline СЕСут Carlos Vallejo Márquez & Miguel Sánchez Castillo & 25 \\
\hline СЕСУт Miguel Bernard & Carlos Rodríguez Rocha & 35 \\
\hline СЕСУт Estanislao Ramírez Ruiz & Carlos Rodríguez Rocha & 35 \\
\hline Casco de Santo Tomás & Angélica Millán & 60 \\
\hline CECYT Ricardo Flores Magón & Miguel Ángel Gutiérrez & 40 \\
\hline СЕСУт Benito Juárez & José Ramírez Silva y María Eugenia Salas & 55 \\
\hline Desarrollo Cultural & Otila Cuesta Grajales & Grupo de Danza del IPN \\
\hline Escuela Superior de Comercio y Administración, Tepepan & María Zoila Nava Meza & 80 \\
\hline Escuela Nacional de Medicina y Homeopatía & Gustavo A. Quezada & 15 \\
\hline Escuela Superior de Ingeniería, Química e Industrias Extractivas & Rafael Téllez Girón & - \\
\hline Centro Interdisciplinario de Ciencias de la Salud & Ma. de la Luz Murguía & - \\
\hline Escuela Superior de Física y Matemáticas & Julio González & - \\
\hline Escuela Superior de Ingeniería y Arquitectura, Tecamachalco & Juan T. Piedra & 15 \\
\hline Escuela Superior de Ingeniería Mecánica y Eléctrica, Zacatenco & Alejandro Guzmán & - \\
\hline
\end{tabular}




\begin{tabular}{l|l|c}
\multicolumn{1}{c|}{ Escuela } & \multicolumn{1}{c|}{ Profesor } & \multicolumn{1}{c}{ Núm. de estudiantes } \\
\hline Escuela Superior de Ingeniería Mecánica y Eléctrica, Culhuacán & María Cristina Estrada & 25 \\
\hline CECyt Juan de Dios Bátiz & Hilda A. Granados y Ofelia E. Campos & 35 \\
\hline CECyT José María Morelos y Pavón & Pablo Parga & 40 \\
\hline CECyт Narciso Bassols & Honoria Baena & 25 \\
\hline CECyт Gonzalo Vázquez Vela & Edith Marlene Martínez & 30 \\
\hline CECyт Walter Cross Buchanan & María de Lourdes de Gante & 20 \\
\hline CECyт Lázaro Cárdenas & Claudio Rivera & 15 \\
\hline CECyt Diodoro Antúnez Echegaray & Margarita E. Aguilar & 65 \\
\hline CECyт Cuauhtémoc & Verónica Aguilar & 35 \\
\hline CECyt Escuela de Enfermería y Obstetricia & Elena Marroquí & 80 \\
\hline CECyt Escuela de Enfermería y Obstetricia & Elena Marroquí & 80 \\
\hline
\end{tabular}

Fuente: IPN, Relación de profesores de danza folclórica, ca. 1984. Documento mecanográfico. Archivo personal de Martín Mendoza Pastrana.

La carga horaria para los talleres de danza era de 10 o 20 horas a la semana y los profesores que tenían 20 podían ir dos días a la semana, cubriendo cinco horas diarias; el resto del tiempo lo utilizaban para atender funciones dentro y/o fuera del plantel.

Con respecto a la forma en que los maestros transmitían sus conocimientos "cada uno tenía su propio método $[\ldots]$ No hubo intención de unificar. El repertorio era el que ellos seleccionaban. Había libertad de cátedra" (Mendoza-Pastrana, 2018). Los objetivos de los talleres de danza folclórica fueron "que los estudiantes conocieran la danza folclórica, su cultura y su país; fomentarles un sentimiento de arraigo e identidad como mexicanos; proporcionarles una educación integral y que la danza folclórica fuera parte de su formación" (Mendoza-Pastrana, 2018).

Además, con la enseñanza de danza folclórica se intentaba "difundir la esencia de las danzas, sones, jarabes, polkas, cuadrillas y otros ritmos de los diferentes estados de la república mexicana, entre ellos, Veracruz, Jalisco, Michoacán, Chiapas, Oaxaca, Nuevo León, Tamaulipas" (IPN, 2008).
En la década de los ochenta el área encargada de difundir los talleres artísticos fue la dirección de Difusión Cultural, que tenía la responsabilidad de elaborar trípticos para distribuirlos en cada una de las escuelas a fin de que los estudiantes conocieran los sitios de inscripción, las escuelas que tenían talleres y el objetivo de los mismos, además incluían mensajes para exhortar a la comunidad a participar en ellos (IPN, 1988).

El número de estudiantes en cada taller dependía de la escuela y del maestro "el grupo de danza del CECyT 'Ricardo Flores Magón' siempre tenía muchos alumnos por lo que era necesario dividirlo de acuerdo con los horarios de las materias académicas, de los estudiantes y del maestro" (MendozaPastrana, 2018). Había tres tipos de grupo: principiantes, intermedios y avanzados y cada uno tenía su programa de trabajo. El acompañamiento musical en las clases era con grabadora y en los teatros y auditorios con equipo de sonido; para las funciones dancísticas también se podía invitar a grupos musicales, siempre y cuando se contara con presupuesto. 
En este periodo, aunque se incrementó el presupuesto para danza, siguió siendo insuficiente para la confección y compra del vestuario, no obstante, los jóvenes continuaron aprendiendo danza folclórica y bailando a pesar de que no tuvieran dinero para comprarse los botines o la falda adecuada.

Aun en dichas condiciones, los talleres de danza folclórica rebasaron las expectativas de sus maestros debido a que se formaron grupos que representaban dignamente a la institución y porque algunos de los estudiantes llegaron a dedicarse profesionalmente a la danza. El excoordinador de danza folclórica menciona: "Hubo estudiantes que se dedicaron a la danza de manera profesional. Algunos llegaron a ser bailarines de la compañía de Amalia Hernández, otros participaron en compañías particulares e incluso hubo bailarines que formaron parte del espectáculo de Juan Gabriel" (Mendoza-Pastrana, 2018).

En la década de los ochenta, debido a la expansión de la danza no sólo en el IPN sino en todo el país, esta disciplina empezó a ocupar espacios alternativos, ya no sólo se practicaba en el salón de usos múltiples, en los pasillos, en los salones de clases, en los foros y en los auditorios, sino que abarcó otros lugares que incluyeron las calles, los museos, las explanadas y las plazas; en el Politécnico se empezó a utilizar la explanada cercana a las oficinas de Difusión Cultural en Zacatenco. Tradicionalmente la explanada estaba destinada a los festejos del IPN, pero se gestionó su uso para las funciones de música y danza y para las celebraciones del Día Internacional de la Danza. En 1983 en ella se presentaron "Los voladores de la sierra norte y los quetzales del estado de Puebla [...] se demostró que la plaza podía abrirse a la cultura y a la danza" (IPN, 2008).

Gracias al trabajo y entusiasmo de los maestros, el número de talleres y de grupos de danza se incrementó. En octubre de 1985, varios grupos del IPN dieron funciones: el 2 de octubre actuó el grupo del CECyT "Lázaro Cárdenas"; el 3 de octubre, el grupo de la Escuela Superior de Comercio y Administración (Tepepan), el 15 de octubre el CECyT "Cuauhtémoc" y en ese mismo mes el Grupo de danza de la Escuela Superior de Ingeniería Mecánica y Eléctrica (Xocongo) de la maestra Cecilia Campos Domínguez llevó a escena la Danza de negritos de la sierra norte del estado de Puebla (IPN, 1985).

Asimismo, el grupo de la Escuela Superior de Física y Matemáticas a cargo de Cecilia Campos bailó el 24 de febrero de 1987 en el Auditorio "A" Alejo Peralta de la Unidad Cultural Jaime Torres Bodet; de la Huasteca potosina interpretaron: El paseador, $E l$ caballito, El toro requezón y El zacamandú; de Jalisco: El huizache, La negra, El son de los aguacates y El jarabe tapatío, y de Nuevo León: La clavelinia, El sapo y la rana, La campanita, El venado, La abuelita. Los bailarines fueron: José Guadalupe Mares Velo, René Santillán Chávez, Óscar Flores Paredes, Bernardo Gutiérrez Sosa, Rafael Pérez Martínez, María del Pilar Buenrostro, Virginia Herrera Campos, Elvia Santillán Gallegos, acompañados del conjunto musical "Los trigueños de Guanajuato" (IPN, 1987).

El movimiento dancístico señalado dio como resultado que varios programas de antaño se recuperaran y que otros se pusieran en marcha, como fue el caso de los Encuentros interpolitécnicos, funciones de danza de grupos del IPN, encuentros de danza, prácticas de campo y cursos con informantes. A continuación, se dan a conocer algunos detalles de los programas artísticos instrumentados en la década de los ochenta.

\section{Encuentros interpolitécnicos}

Fue un programa en el que los grupos de danza de las diferentes escuelas del IPN se reunían para mostrar su trabajo y se premiaba a los más destacados; se iniciaron con el propósito de "preservar y difundir las costumbres y tradiciones de México; despertar el interés de otros estudiantes para que se inscribieran en los talleres artísticos y proporcionarles una educación integral” (IPN, 2008). 
El coordinador de danza folclórica menciona cómo surgió la idea de organizarlos:

\begin{abstract}
en una ocasión el director general nos convocó a todos los coordinadores de área para decirnos que era necesario hacer algo fuerte con respecto a la cultura para que el Poli se conociera más en ese ámbito y nos pidió que pensáramos en algún proyecto. Yo le propuse que hiciéramos los concursos Interpolitécnicos. $\mathrm{Al}$ director le interesó y me dijo que hiciera el proyecto, se lo presenté, le gustó y lo autorizó. Desde el primer momento fue un éxito. Hasta la fecha el IPN los sigue organizando (Mendoza-Pastrana, 2018).
\end{abstract}

Se clasificaban en dos categorías: escuelas de nivel medio superior y escuelas de nivel superior; su participación se dividía en dos etapas. En la primera, en cada escuela se seleccionaba al grupo que los representaba, y en la segunda se elegía a los grupos semifinalistas, los que bailaban en los auditorios de la Unidad Cultural de Zacatenco. El jurado para la decisión final estaba integrado por personalidades de reconocido prestigio en la disciplina y el premio para los primeros lugares era dinero en efectivo. Los encuentros interpolitécnicos se abrieron para motivar a los grupos de danza y para: "fomentar la investigación dancística y creatividad de los profesores [para profundizar en el estudio de] danzas étnicas, baile popular mexicano luciendo escenografías y coreografías de fiestas costumbristas como bodas, bautizos, ceremonias religiosas, guerreras o comparsas de carnaval alusivas a la historia de México" (IPN, 2008).

En la década de los ochenta se celebraron varios encuentros: el primero tuvo lugar al término del ciclo escolar 1982-1983 y el ganador fue el grupo de Pablo Parga que llevó a escena la Danza de Concheros. El segundo se organizó con la participación de los talleres de danza mexicana (étnica y regional), danza moderna, ballet clásico y artes plásticas del ciclo escolar 1983-1984; los grupos se presentaron en el auditorio "A" Ing. Alejo Peralta de la Unidad Cultural "Jaime Torres Bodet" en Zacatenco los días 23, $26,27,28,29$ y 30 de noviembre a partir de las 11 horas (IPN, 1984a). En esa ocasión el grupo del CECyT Juan de Dios Bátiz bailó la Danza de los Guaguas de Papantla, Veracruz (IPN, 1984b) también actuaron grupos de diferentes instituciones (IPN, 1984c) y se convocó a los jóvenes para que participaran en los concursos de poesía, declamación y lectura en voz alta (IPN, 1984d).

El tercer encuentro se celebró en marzo-junio de 1985 con los jóvenes inscritos en los talleres de danza del ciclo escolar 1984-1985 y en esa ocasión el conjunto ganador fue el del profesor Rafael Téllez Girón, quien presentó Danza de Coras; el $2^{\circ}$ lugar lo obtuvo el grupo de Cecilia Campos Domínguez con Danza de los negritos, quien platica una anécdota:

En 1985 sacamos el $2^{\circ}$ lugar, el jurado estuvo compuesto por Emma Duarte, Noemí Marín y Tizoc. Ya nos iban a descalificar porque el maestro Vidal me prestó los botines para los muchachos y llegó corriendo; los muchachos se tardaron en entrar porque se los estaban probando y no les quedaban. Finalmente me perdonaron y sacamos el $2^{\circ}$ lugar. Participamos con la Danza de los negritos de Puebla, montamos un cuadro costumbrista, no sólo la danza, sino que incluimos una procesión de la festividad de los negritos y la fiesta patronal (Campos, 2018).

Los bailarines fueron: René Santillán Chávez, Óscar Flores P, Bernardo Gutiérrez S., José Guadalupe Mares, José Luis Álvarez Cabrera, Yacara Delgadillo Coronel, Hilda Martínez Reyes, Rosa Ma. Mónica Rojas Cruz, Ma. Eugenia Santillán Gallegos, Ma. de Lourdes Morán Reyes, Cecilia López Orta, Andrés Gutiérrez Mejía, Juan Antonio Martínez Suárez, Carmelo Martínez Suárez y Pablo Martínez Suárez de la ESIME (Xocongo) y bailaron El paseador, El caballito, El toro requesón, Zacamandú y Danza de Negritos (IPN, 1985). 
El quinto encuentro formó parte de los festejos del 50 aniversario del IPN (1936-1986), las actividades que se incluyeron fueron las semifinales de los encuentros de danza clásica, contemporánea y folclórica; una exposición de los trabajos elaborados en los talleres de artes plásticas que duró del 7 al 30 de abril; la muestra de los trabajos de los talleres de pantomima, coros, rondallas, estudiantinas, poesía, caricatura política y oratoria del 6 al 30 de mayo en el Auditorio "A" Zacatenco. Los grupos de danza folclórica que participaron fueron de las escuelas: Superior de Ingeniería Textil, Superior de Ingeniería y Arquitectura (Zacatenco), Nacional de Ciencias Biológicas, Superior de Medicina, Superior de Comercio y Administración (Tepepan), CECyT Miguel Othón de Mendizábal, Unidad Profesional Interdisciplinaria de Ciencias Sociales y Administrativas y CECyT Gonzalo Vázquez Vela. De danza clásica y de contemporánea bailó sólo un grupo de cada disciplina, ambos mostraron su trabajo en el Auditorio "A" Alejo Peralta (IPN, 1986).

En 1987 tuvo lugar el sexto encuentro interpolitécnico y en esa ocasión el grupo ganador fue el de María Cristina Estrada Navarro quien recuerda: "después del temblor del 85 tuvimos que irnos a la Escuela Superior de Comercio y Administración de Tepepan y fusioné ese taller con el de la Escuela Superior de Ingeniería Mecánica y Eléctrica de Culhuacán; se formó un grupo fuerte que ganó en 1987. El repertorio con el que obtuvimos el primer lugar fue Tamaulipas" (Estrada, 2021).

En 1989 el tercer lugar lo obtuvo el grupo del CECyT dirigido por José Luis Rodríguez Cuevas, con Danza de Matlachines de Tuxpan, Veracruz. Hay registro de que a partir de 1991 a estos encuentros se les llamó concursos y el de este año se efectuó el 27 de febrero en el auditorio "Lenin" en el Casco de Santo Tomás; el protocolo consistió en palabras de bienvenida, presentación de autoridades, presentación del jurado, relación de grupos participantes (según sorteo previo), deliberación del jurado, premiación del primero, segundo y tercer lugar, y despedida.
Los requisitos para inscribirse, según la convocatoria del 9 de enero de 1991, fueron que podrían participar todos los alumnos y los talleres de danza folclórica del IPN, siempre y cuando entregaran la monografia de las danzas y bailes que iban a interpretar y que el trabajo escénico fuera mayor a 15 minutos.

Los aspectos a evaluar fueron: autenticidad, grado de dificultad, ritmo y precisión, coreografía, vestuario, organización del grupo; los premios consistieron en: primer lugar $\$ 400000$; segundo lugar $\$ 300000$ y tercer lugar $\$ 200000$ (IPN, 1991). Después de algunos años a los Concursos interpolitécnicos se les dio el nombre de un maestro destacado de danza folclórica, como fue el caso de los concursos que han llevado el nombre de: "Miguel Ángel Gutiérrez Badillo", "Martín Mendoza Pastrana", "Carlos Rodríguez Rocha" (2015) y "Alejandro Guzmán Miranda" (2018).

\section{Funciones de danza de los grupos del IPN}

Son las actuaciones dancísticas que los grupos de las diferentes escuelas de la institución presentan en las instalaciones del IPN o fuera de ellas y en las que los estudiantes de danza muestran los avances que han logrado; hasta la fecha los conjuntos de danza han participado en homenajes, coloquios y encuentros organizados por la propia entidad educativa, así como en ceremonias y festividades de otras instituciones como:

en el Festival Gervantino en Guanajuato, en las Jornadas Alarconianas en Taxco Guerrero, en las Callejoneadas en Querétaro, en los Festivales de Aniversario del IPN (cívicos y religiosos), en las ferias regionales en diferentes estados de la república: Tlaxcala, Oaxaca, Puebla, San Luis Potosí, Estado de México. En los homenajes a personajes de la historia, en concursos, muestras, encuentros, torneos deportivos, graduaciones y bienvenidas a los estudiantes del IPN (IPN, 2008). 
Una velada inolvidable para la comunidad politécnica fue la que tuvo lugar el 29 de mayo de 1984 en el Auditorio "A" Alejo Peralta de la Unidad Cultural "Jaime Torres Bodet" porque ese día se recordó a Marcelo Torreblanca y varios grupos bailaron en su honor (IPN, 1984d).

\section{Encuentros dancísticos del IPN}

Consistían en que el Politécnico invitaba a grupos de danza de otras instituciones a sus celebraciones. Algunos de los invitados fueron la UNAM, el ISSSTE, el Colegio de Bachilleres, el IMSS, el Patrimonio Cultural del Estado de México, el Gobierno de Hidalgo, la Escuela Nacional Preparatoria de la UNAM; este programa duró poco tiempo porque "el intercambio se hacía como amigos. El IPN sólo les proporcionaba el transporte, el foro para presentarse y un reconocimiento" (Mendoza-Pastrana, 2018).

\section{Prácticas de campo y cursos con informantes}

Estos programas continúan vigentes y se realizan por petición e iniciativa de los docentes. Para organizar los cursos de capacitación con informantes, el maestro Martín Mendoza comenta que "al informante se le invitaba dos o tres días, porque se le pagaba el pasaje y gastos. Algunos de los cursos que se impartieron fueron: sones huastecos de Hidalgo y de Puebla y otras danzas y bailes de acuerdo con el repertorio que los maestros iban a trabajar". Martín Mendoza Pastrana concluyó su labor como coordinador de danza folclórica en el IPN en 1992 y de su paso por el Politécnico dice:

Mi mayor logro fue continuar con el trabajo del maestro Marcelo Torreblanca. Él echó su semilla, la semilla creció y nosotros la regamos, generamos una gran participación y compromiso de los estudiantes del IPN. Logramos que los docentes de danza folclórica aplicaran sus conocimientos y que estuvieran a gusto a pesar de que no ganaban mucho dinero; logramos difundir la danza y que se promoviera la institución (Mendoza-Pastrana, 2018).

\section{Conclusiones}

Frente a este panorama podemos decir que los talleres artísticos del IPN han transitado por tres momentos, el primero, los antecedentes, que se caracterizó porque la difusión de la cultura se compartía entre las autoridades del IPN y los clubes, los orfeones y los ateneos, que eran asociaciones de jóvenes y docentes que participaban activamente en la difusión de la cultura; esta estrategia sufrió cambios a partir del movimiento estudiantil de 1968, cuando la institución revisó la pertinencia de dichas formas de sociabilidad y las dejó de lado para asumir totalmente la responsabilidad de dicha tarea.

El segundo momento se caracterizó porque los talleres artísticos se instauraron en la mayor parte de las escuelas, se formaron grupos representativos de danza y los maestros se empeñaron en demostrar que la danza requería un trabajo de investigación fundamentado en prácticas de campo y en cursos con informantes.

El tercer momento se identificó por la consolidación de los talleres y por la contratación de nuevos maestros, quienes contaron con el apoyo de las coordinaciones que estaban encabezadas por especialistas.

Una de las ventajas de que las autoridades tomaran en sus manos la difusión de la cultura fue que se dieron cuenta de que el área de danza tenía carencias en el ámbito presupuestal, situación que se fue subsanando, a medida que los maestros demostraron la importancia de hacer investigación y las autoridades le asignaron mayor presupuesto, aunque, cabe señalar, nunca fue suficiente. La desventaja que se advierte es que la libertad, creatividad e iniciativa de los estudiantes fue coartada, desde el momento en que ya no se les permitió participar directamente en las labores de difusión de la cultura. 
En cuanto a los maestros, se pudo identificar que la mayoría de ellos fueron profesionales que contaban con una formación sólida como docentes, bailarines y/o investigadores y que estaban comprometidos con el IPN, con la danza y con los estudiantes y no escatimaron tiempo, esfuerzo ni dinero para que los bailarines acudieran a prácticas de campo, a cursos con informantes y vistieran correctamente de acuerdo con las danzas que interpretaban.

Con respecto a los talleres de danza, se detectó que el IPN buscó varios propósitos, entre ellos, la producción, preservación y difusión de la cultura a fin de fortificar la identidad nacional de los estudiantes; intención no lejana, desde el momento en que los estudiantes tuvieron la oportunidad de asistir al lugar de origen y a las festividades de donde provenían las danzas, lo que posibilitó que se involucraran en ellas y que de alguna manera se apropiaran e interiorizaran, al menos parcialmente, del complejo simbólico-cultural del que formaban parte.

Otro propósito fue proporcionarles a los estudiantes una educación integral, intención que puede decirse se alcanzó, porque en los procesos de enseñanza aprendizaje de las artes todos se involucran y pueden ser protagonistas: los participantes, el intercambio de conocimientos, la producción colectiva de aprendizajes y la integración de teoría y práctica - desde el momento en que se busca "aprender haciendo" y se "hace aprendiendo" - y porque el taller, como modalidad educativa para la enseñanza de las artes, resulta idóneo debido a que la "formación del músico o el artista en general [requiere de una] gran dosis de educación personalizada que [...] nos remite, sin más, al núcleo formativo del mundo artesanal, a la cualidad de la relación maestro-aprendiz"
(Semeraro, 1996: 27), en la que se conserva una visión completa de los procesos porque "no sólo el maestro, sino inclusive el más joven aprendiz era capaz de dominar las diversas facetas del proceso productivo"(ibid.), situación que propicia que los implicados se sientan identificados con su obra y proyecten en ella su singularidad y su identidad.

Aunado a lo anterior en los talleres artísticos fue posible recuperar el esparcimiento, el juego, la diversión porque en ellos no sólo encontramos al homofaber, sino también homo ludens, y en este sentido me parece pertinente traer a colación un comentario de María Esther Aguirre Lora (1996: 17) cuando señala: "el artesano juega e inventa. Se da un innegable vínculo del placer con su labor y es aquí donde encontraremos uno de los más importantes aprendizajes para nuestro presente académico: la recuperación del vínculo del placer con nuestro trabajo, mediado por una mirada de asombro y juego, de descubrimiento y creatividad".

El movimiento dancístico mencionado trajo consigo, como ya vimos, la generación de diversos programas, entre los que figuran la creación de grupos representativos, los encuentros interpolitécnicos, funciones de danza de grupos del IPN, encuentros de danza con otras instituciones, prácticas de campo y cursos con informantes. Esta efervescencia, sin duda, dejó una impronta en varios estudiantes mostrándoles la importancia del trabajo colectivo, la disciplina y la solidaridad; o como a Leonel, ayudándolo a modificar su desempeño social e impulsándolo a romper sus barreras y decidirse a bailar, o como en el caso de otros jóvenes, quienes acudieron a los talleres artísticos y la danza los cautivó y los inspiró a elegirla como profesión y forma de vida. 


\section{Referencias}

Aguirre, María Esther (1996), "Presentación de la edición mexicana", Nostalgia del maestro artesano, México, UNAM/CESU, pp. 9-22.

Calvillo, Max y Lourdes Ramírez (2006), Setenta años de historia del Instituto Politécnico Nacional, Tomo II, México, IPN.

Instituto Politécnico Nacional (IPN) (ca. 1984), Relación de escuelas, maestros de danza y estudiantes del taller de danza folclórica del IPN, México, IPN.

IPN (1984a), Invitación para el II Evento Interpolitécnico de Talleres Culturales (Auditorio "A" Alejo Peralta, Unidad Gutural "Jaime Torres Bodet" Zacatenco), México, IPN. IPN (1984b), Programa de mano CECyT Juan de Dios Bátiz, "Encuentro Interpolitécnico de Danza", México, IPN. IPN (1984c), Gartel para el II Evento Interpolitécnico de Talleres Culturales y los concursos de poesía, declamación y lectura en voz alta, México, IPN.

IPN (1984d), Invitación a la "Velada dancística" (Auditorio "A" Alejo Peralta de la Unidad Cultural "Jaime Torres Bodet”), México, IPN.

IPN (1985), Programa de mano, $2^{a}$ etapa del III Encuentro de Danza Folklórica (Auditorio A. Ing. Alejo Peralta Unidad Cultural Zacatenco), México, IPN.

IPN (1985b), Programa de mano. Taller de Danza Folklórica de la Escuela Superior de Ingeniería Mecánica y Eléctrica (Xocongo) (Auditorio "A" Ing. Alejo Peralta, Unidad Cultural Zacatenco), octubre, México, IPN.

IPN (1986), Programa de mano, $V$ Evento Interpolitécnico de talleres artístico-culturales, México, IPN.

IPN (1987), Programa de mano del Taller de Danza Folklórica de la Escuela Superior de Física y Matemáticas (Auditorio "A" Ing. Alejo Peralta, Unidad Cultural Zacatenco), 24 de febrero, México, IPN.

IPN (1988), Tríptico para la difusión de los talleres de danza, Dirección de Difusión Cultural del IPN, México, IPN. IPN (2008), Folleto Conmemorativo, "50 años de la danza en el IPN”'(1958-2008), México, IPN.
IPN (1991), Programa de mano, Escuela Superior de Economía (Auditorio Lenin del IPN), México, IPN.

Mendoza, Cristina (1990a), "La danza como sacerdocio: Beatriz Carrillo", en Una vida dedicada a la danza 1990, Cuadernos del Cenidi Danza, núm. 22, México, Cenidi Danza/INBA, pp. 21-24.

Mendoza, Cristina (1990b), "Helena Jordán y el impulso creativo", en Una vida dedicada a la danza 1990, Cuadernos del Cenidi Danza, núm. 22, México, Cenidi Danza/ INBA, pp. 47-50.

Santoni, Antonio (2009), Vestimenta larga y vestimenta corta. Barberos-cirujanos, nodrizas y parteras como educadores, Puebla, Benemérita Universidad Autónoma de Puebla. Santoni, Antonio (1996), Nostalgia del maestro artesano, México, UNAM/CESU.

Semeraro, Angelo (1996), "Prólogo", en Nostalgia del maestro artesano, México, UNAM/CESU, pp. 23-31.

\section{Entrevistas individuales}

- Martín Mendoza-Pastrana, en la ciudad de México, 5 de febrero de 2018, inédita.

- Cecilia Campos Domínguez, en la ciudad de México, 5 de febrero de 2018, inédita.

- Esperanza Gutiérrez, en la ciudad de México, 11 de julio de 2019, inédita.

- José Luis Rodríguez Cuevas, en la ciudad de México, 18 de septiembre de 2019, inédita.

\section{Entrevistas grupales}

- Martín Mendoza-Pastrana, Cecilia Campos, José Ramírez Salas (hijo de José Ramírez Silva) y Miguel Ángel Gutiérrez-Badillo, en la ciudad de México, 2 de septiembre de 2019, inédita.

\section{Conversación telefónica}

- Miguel Ángel Gutiérrez-Badillo, 25 de mayo de 2021.

- María Cristina Estrada, 26 de mayo de 2021.

- Martín Mendoza-Pastrana, $1^{\circ}$ de junio de 2021.

Cómo citar este artículo:

Ramos-Villalobos, Roxana-Guadalupe (2022), “Talleres de danza del Instituto Politécnico Nacional (ca. 1968-1988)”, Revista Iberoamericana de Educación Superior (RIES), vol. XIII, núm. 36, pp. 84-100, DOI: https://doi.org/10.22201/iisue.20072872e.2022.36.1185 [Consulta: fecha de última consulta]. 